\title{
Fuzzy Failure Modes and Effects Analysis Using Summative Defuzzification Methods
}

\author{
László Pokorádi ${ }^{1}$, Sinan Koçak ${ }^{2}$, Edit Tóth-Laufer ${ }^{1}$ \\ ${ }^{1}$ Óbuda University, Institute of Mechatronics and Vehicle Engineering \\ Népszínház u. 8, 1081 Budapest, Hungary \\ pokoradi.laszlo@bgk.uni-obuda.hu; laufer.edit@bgk.uni-obuda.hu \\ ${ }^{2}$ Óbuda University, Doctoral School on Safety and Security Sciences Budapest, \\ Hungary; sinan.kocak@bgk.uni-obuda.hu
}

\begin{abstract}
Nowadays, in order to achieve competitiveness in the manufacturing industry, quality and reliability in design and manufacturing processes are essential factors. These requirements can only be fulfilled by using effective estimation models, instead of the costand time-consuming measurements. The widely used engineering technique Fuzzy-based Failure Modes and Effects Analysis (F-FMEA) also serves this purpose. This method is able to identify and eliminate potential problems of a product from the process, system, design, and service based on the available data to avoid possible risk (i.e. repetition of damage and additional costs). Data can be analyzed properly assessing the Probability of Failure (PoF), Consequence of Failure (CoF), and Detectability of Failure (DoF) using a fuzzy-based model, which can work well in situations where there is not enough data for a statistical model. Authors investigate different defuzzification methods in F-FMEA, and propose a novel Summative defuzzification to combine the results of the different fuzzy subsystems.
\end{abstract}

Keywords: Fuzzy logic; FMEA; Defuzzification; Summative Defuzzification

\section{Introduction}

Nowadays, due to increased quality requirements, it has become vital to optimize the manufacturing process. Technological advances make it possible to improve the quality and reliability of the manufactured workpiece and the process itself. However, measuring all possible settings and parameters, which affect the quality requirements is cost- and time-consuming, and in some cases is not possible at all. Several problem-solving techniques are available to handle this issue, such as Lean Manufacturing, Six Sigma, Statistical Engineering, Lean Six Sigma [2]. The widely used engineering technique Failure Modes and Effects Analysis (FMEA) also serves this purpose [1]. It is a systematic quality improvement method aimed at preventing any possible defects, which may occur in the system, 
design, process, or services. This approach was first used in 1949 by the United States Military to reduce variation sources and possible failures associated with ammunition production, therefore, has proven to be highly effective [3]. This was followed by FMEA and was developed by NASA at the end of the 1960s to be used in the aerospace industry [4]. This technique has been advanced and popularly adopted until today and used in the aerospace sector, the automobile industry, the chemical industry, and in all technology-weighted areas.

Since risk has been defined as the severity and probability of a given hazard, risk prediction is usually based on a quantitative assessment of the risk level and likelihood of occurrence [5]. However, both quantitative and qualitative parameters can be observed among the risk factors, which should be handled adequately in order to obtain realistic results. Consequently, only that method should be used which can handle both types of inputs during the evaluation. The fuzzy approach fulfills these requirements; thus it is a useful method in risk management that solves the uncertainty and subjectivity of the data and the evaluation process [6]. It is a mathematical approach with a decision-making mechanism without sharp limits, in this way it mimics human logic. The concept of fuzzy logic and related fuzzy set theory was introduced and published in 1965 by Lotfi A. Zadeh to handle mathematical concepts that are difficult to quantify [7]. In the classical set concept, an element is either a member of a set or not. However, in fuzzy logic, the degree of specified membership ranges is accepted between 0 and 1 [8]. This approach serves as a more realistic solution to daily life problems because it has a more flexible structure. In 1975, the fuzzy logic inference was operated by Mamdani and Assilian as the first effort to control the steam engine and boiler combination [9]. In light of these studies, fuzzy logic has become a popular and widely-used technique in many areas, such as industrial, aerospace, electrical, mechanical, mechatronics, computer, chemical, biomedical, environmental, agricultural, geological, etc. [20].

The Fuzzy Failure Modes and Effect Analysis (F-FMEA) integration approach is an extension of the traditional FMEA method and has been used since the mid1990s. The first Fuzzy logic-based Failure Mode, Effects, and Criticality Analysis is connected to the names of Bowles and Peláez, which was used to first describe the prioritization of failures regarding to the corrective actions [10]. The authors proposed two different, but related approaches for assessing criticality. The first one to operate with numerical rankings, based on the aggregated opinions of the experts or obtained from a reliability analysis, and use crisp values. It is applied in the traditional risk priority number (RPN) calculation. However, in the design process, qualitative factors should also be considered, where less detailed information is available. Consequently, the second approach allows these kinds of fuzzy inputs, and linguistic terms can be assigned to the RPN calculation as ranking.

In current literature, there are numerous case studies in the field of F-FMEA. The recent studies of Jakkula, Mandela, and Chivikula's publications are valuable 
additions aimed at the FMEA risk assessment approach for the Load Haul Dumper (LHD) machine [11]. The authors analyzed the LHD's failure behavior in every potential failure mode that provided information on various aspects, such as the current operating state of the machines, the reasons for the failure modes occurring, the effect of the failure modes on the equipment performance, and reliable life, etc. Moreover, these investigations evaluated estimates of required management practices or control measures such as possible design changes and replacement of components to ensure the necessary level of usability and utilization.

Further, Kelvin, Jason, Chee-Wah, and Alan have studied the new product development in the flexible electronics industry using the application of Fuzzybased FMEA [12]. The goal of the paper was to minimize the risks of developing new products for high-tech enterprises in a short time. Therefore, the authors developed a unique methodology to make the product reliable for a long time by prioritizing critical failure mode using F-FMEA.

The bearing is an ubiquitous, essential part of the machine-building industry, used to move and rotate all kinds of machines. The fatigue of the bearing depends on the ambient conditions, the load, and the mechanical strength of the parts that make up the bearing [1] [14] [15] [16].

This paper aims to develop novel fuzzy rule-based risk assessment methods using summative defuzzification in F-FMEA model. Three criteria are calculated to define the Risk Priority Number $(R P N)$; the Probability of Failure $(P o F)$, the Consequence of Failure $(C o F)$, and the Detectability of Failure $(D o F)$. This can be achieved by comparing the result of the traditional defuzzification methods, and the authors propose a novel summative defuzzification to combine the results of the different fuzzy subsystems.

The paper is structured as follows: Section 2 presents the FMEA methods. In Section 3 the proposed novel Summative defuzzification methods are presented. Section 4 illustrates the use of proposed methods for risk assessment of bearing manufacturing process as a case study. Section 5 is devoted to the conclusion.

\section{The Failure Mode and Effect Analysis}

The Failure Modes and Effects Analysis (FMEA) is one of the well-known reliability analysis methods. The FMEA was developed in the USA; Martin Marietta and Boeing companies published an engineering manual on the general method back in 1957. The FMEA method was successfully employed quite early within the frame of the Apollo Moon landing program after astronauts Grissom, White and Chaffee had died on board Apollo 1 during a ground test. 


\subsection{The Original (crisp) FMEA}

The IEC Standard Publication 812 [4] documented how to carry out the "original" FMEA. During the analysis, experts investigate process or system, determine its potential failures and their efficient causes. Criticality level $\left(R P N_{i}\right)$ of the determined $i^{\text {th }}$ cause is assessed depending on Probability of Failure $\left(P o F_{i}\right)$, Consequence of Failure $\left(C o F_{i}\right)$, and Detectability of Failure $\left(D o F_{i}\right)$, based on the following multiplication

$$
R P N_{i}=\mathrm{CoF}_{i} \cdot \mathrm{PoF}_{i} \cdot \mathrm{DoF}_{i}
$$

Using the results and ranking of $R P N \mathrm{~s}$, experts propose actions to improve the reliability of the investigated system or process. From time to time, additional requirements can be applied. For example, (see Table 3 and Table 4):

"If $C o F_{i}>5$, then Action is Needful".

if there is not enough data available to experts for statistical modeling, for "crisp" FMEA, estimated parameters should be used. Different linguistic interpretations may result in some inaccuracy, which should be handled by the experts. One of the possible tools for this purpose is the Fuzzy Rule-based FMEA (F-FMEA). The F-FMEA seems to be a powerful mathematical approach, which is capable of combining linguistic and numeric variables in order to estimate the subjectiveness involved in FMEA.

\subsection{Traditional Fuzzy Rule Based F-FMEA}

The traditional fuzzy decision process consists of the following sub-processes: fuzzification, inference (firing strength calculation, and implication), composition, and defuzzification (Figure 1). In certain cases the composition and defuzzification processes are combined.

In the fuzzification sub-process, crisp input values are converted into membership values to define the extent to which the value belongs to the fuzzy sets, which are described using linguistic variables. The predefined fuzzy membership functions for the input parameters represent the mean of experts opinion. These fuzzified values are used in further computations.

The inference sub-process consists of the firing strength calculation and implication. The firing strength calculation is used to combine the membership values of the different input parameters using a conjunction, or disjunction operator. The result of this step represents the truth-value of the rule antecedent for each rule. After evaluating the condition part of the rule, the consequence of the same rule should be considered, using a conjunction operator in the implication step. In this step, the extent of the given rule consequence is involved in the output is examined. 


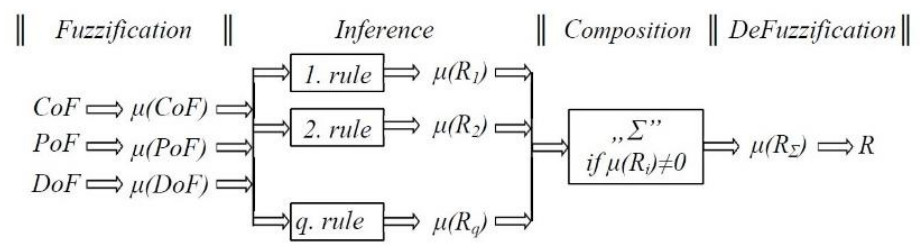

Figure 1

Traditional fuzzy process flow-chart (source: [17])

The above steps are performed for all the rules. In the composition sub-process, the obtained fuzzy sets (i.e. rule consequence after the inference) are aggregated that occur in the fuzzy rule base. This sub-process results in a single, but complex set. It combines the result of the inference of each rule and determines the output of the system.

The last sub-process is defuzzification, which is used to generate a crisp value to represent the output fuzzy set in the best possible way.

\subsection{F-FMEA with Summative Defuzzification}

The above-mentioned traditional methods can be used effectively when the analysis is performed based on the opinion of a single expert. However, the analysis becomes more reliable if it is considered with multiple opinions if they are available. This type of analysis requires a modified method to obtain a more pronounced result. To address this issue authors, a novel method, so-called Summative defuzzification (SDF) is proposed. This technique calculates the average of the different defuzzified crisp values obtained from different experiences by applying the determined defuzzification method again.

In all cases, the results are considered up to the composition sub-processing of the fuzzy inference process described in Section 2.2. Figure 2 shows the inference process of the SDF fuzzy model for the case where the analysis is performed based on two opinions.

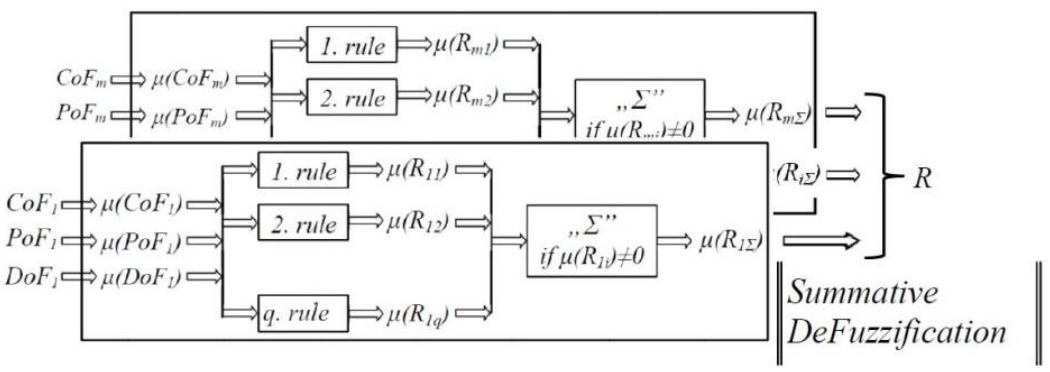

Figure 2

Flow cart of Fuzzy inference with summative defuzzification (source: [21]) 


\section{Summative Defuzzification Methods}

Defuzzification is the final sub-process, which transforms the fuzzy set to a crisp value of criticality. This value will be obtained in such a way as to best represent the aggregated fuzzy set. As a result of the fuzzy inference mechanism, the defuzzified crisp value shows the action to be considered in process control. As for which method is the most appropriate, that can always be determined by the task. In this section, the two most commonly used traditional defuzzification methods are presented. These methods are applied in the proposed novel approach.

\subsection{Traditional Defuzzification Methods}

First a short overview is given about traditional fuzzy rule based F-FMEA, followed by the introduction of summative defuzzification.

\subsubsection{Center of Gravity (CoG) Method}

The Center of Gravity ( $\mathrm{CoG}$ ) method is one of the most frequently used defuzzification methods. It defines the center of gravity under the curve, considering overlapping areas more times.

The following equation defines the crisp result of the centroid defuzzification method.

$$
R_{C o G}=\frac{\sum_{i=1}^{n} \int_{-\infty}^{\infty} \mu_{i}(z) z d z}{\sum_{i=1}^{n} \int_{-\infty}^{\infty} \mu_{i}(z) d z},
$$

where $n$ is the number of sub-conclusions, $\mu_{i}$ is truth value of the $i^{\text {th }}$ subconclusion.

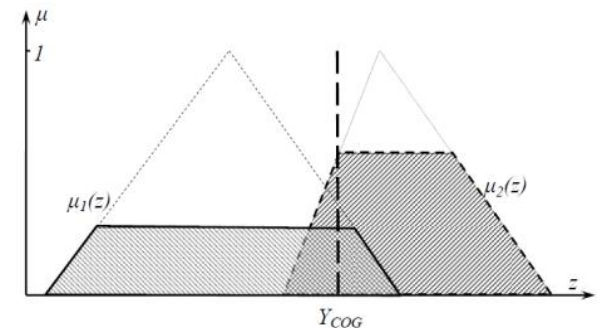

Figure 3

Centre of Gravity Defuzzification Method (source: [22]) 


\subsubsection{Center of Area (CoA) Method}

The CoA method is similar to the Center of Gravity method. The difference between the two methods is that the center of gravity method takes into account the overlapped areas of sub-conclusions multiple times, whereas the center of area method only takes into account them only once (see Figs. 3 and 4). The major disadvantage of CoA, as compared with the Center of Gravity method, is that it is very difficult to calculate it in the case of complex shape partial conclusions [18].

$$
R_{C o A}=\frac{\int_{-\infty}^{\infty} \mu_{\Sigma}(z) z d z}{\int_{-\infty}^{\infty} \mu_{\Sigma}(z) d z},
$$

where $\mu_{\Sigma}$ is the maximum height of the conjunct set of sub-conclusions.

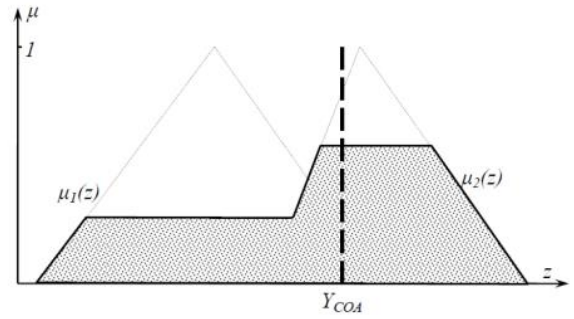

Figure 4

Centre of Area Defuzzification Method (source: [22])

\subsection{Summative Defuzzification Methods}

In the F-FMEA model it is vital to take into account the available multiple opinions because it makes the analysis more reliable. However, in the case when more different observations are available, the traditional inference process should be modified. This sub-section introduces the theoretical basics of the proposed novel method.

\subsubsection{Summative Center of Gravity Defuzzification (SCoG)}

In this method, the aggregated fuzzy set representing the expert opinion should first be determined considering overlapping areas more times (as is the case of the COG method). Then, in order to combine the resulting sets of the different experts to gain the system output based on the summary opinion, the CoG method is used on the fuzzy sets obtained for different opinions.

The crisp value of summative Centroid defuzzification method $\left(R_{S C o G}\right)$ is defined by the equation 


$$
R_{S C o G}=\frac{\sum_{j=1}^{m} \sum_{i=1}^{n} \int_{-\infty}^{\infty} \mu_{j i}(z) z d z}{\sum_{j=1}^{m} \sum_{i=1}^{n} \int_{-\infty}^{\infty} \mu_{j i}(z) d z},
$$

where $m$ is the number of the different expert groups, $n$ is the number of subconclusions, $\mu_{j i}$ is the truth value of the $i^{\text {th }}$ sub-conclusion in the case of the $j^{\text {th }}$ expert opinion. Figure 5 illustrates the sub-conclusions to be considered separately because the CoG method defines the center of gravity under the curve, considering overlapping areas more times. The overall output set of the system can be generated as a composition of Opinion 1 and Opinion 2.

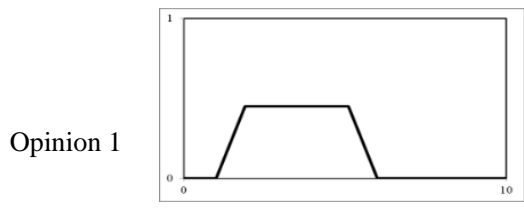

sub-conclusion 1

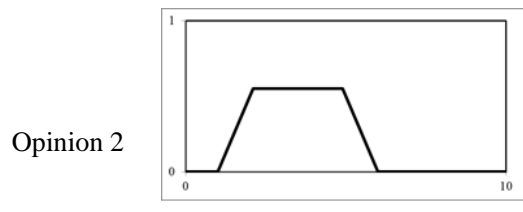

sub-conclusion 1

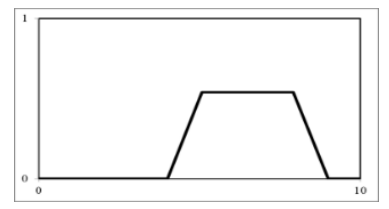

sub-conclusion 2

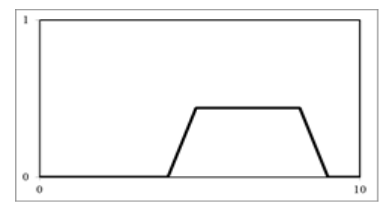

sub-conclusion 2

Figure 5

Sub-conclusions of the Failure 'A1' in the Case Study

\subsubsection{Combined CoA and CoG Summative Defuzzification (SCoAG)}

This version of the Summative defuzzification is a combination of the traditional CoA and CoG methods.

First, the aggregated fuzzy set representing the expert opinion should first be determined considering overlapping areas only ones (as is the case of the COA method) to determine the conclusion sets of different opinions. Then, the obtained fuzzy sets should be combined using the Center of Gravity method.

$$
R_{S C o A G}=\frac{\sum_{j=1}^{m} \int_{-\infty}^{\infty} \mu_{\Sigma}(z) z d z}{\sum_{j=1}^{m} \int_{-\infty}^{\infty} \mu_{\Sigma}(z) d z}
$$


where $m$ is the number of the different expert groups.

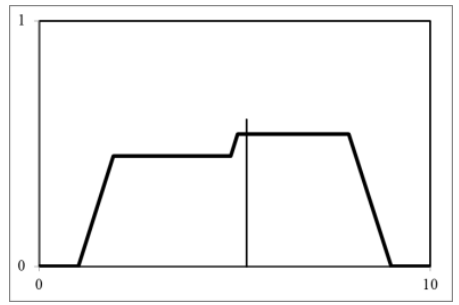

area of the opinion 1

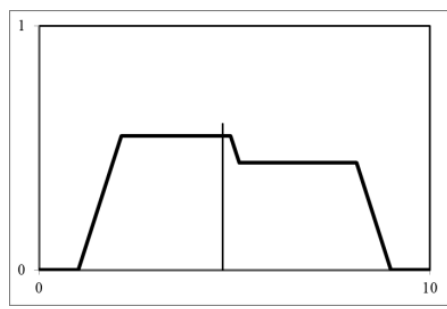

area of the opinion 2

Figure 6

Areas of the Opinions of the Failure 'A1' in the Case Study

\section{Case Study}

As a case study, the authors investigated an F-FMEA system for assessing the risk of the bearing manufacturing process to demonstrate the usage of summative defuzzification, and the results are compared to the results of publication [1]. For comparability, the same inputs are considered in the modified system, which were used in publication [1]. Although the original system analyzed the opinions of two different expert groups on average, the Summative-defuzzificationsupported F-FMEA inference took the opinions into account separately. The failure codes are listed in Table 1, and the related inputs are shown in Table 2, including both individual and average opinions of Team 1 and Team 2. During the evaluation, trapezoidal fuzzy membership functions are used, which are defined by Figure 7, and Equation (6). 
Table 1

Failure codes

\begin{tabular}{|c|c|c|c|c|}
\hline Function & $\begin{array}{l}\text { Failure } \\
\text { mode }\end{array}$ & Failure effect & Code & $\begin{array}{c}\text { Occasion } \\
\text { (occurance) }\end{array}$ \\
\hline \multirow{6}{*}{$\begin{array}{c}\text { Outer } \\
\text { diameter } \\
\text { of } \\
\text { bearing }\end{array}$} & \multirow{2}{*}{ Big } & \multirow{2}{*}{$\begin{array}{c}\text { installation } \\
\text { problem, } \\
\text { short fatigue life }\end{array}$} & B1 & adjusting of a machine \\
\hline & & & B2 & omission of finishing \\
\hline & \multirow{4}{*}{ Small } & \multirow{4}{*}{$\begin{array}{l}\text { slack-running fit, } \\
\text { early failure }\end{array}$} & A1 & breakage of cone belt \\
\hline & & & A2 & $\begin{array}{l}\text { improper emulsion } \\
\text { concentration }\end{array}$ \\
\hline & & & A3 & $\begin{array}{c}\text { Continuity of charging is } \\
\text { improper }\end{array}$ \\
\hline & & & A4 & Congestion before finishing \\
\hline
\end{tabular}

Table 2

Input Data of FMEAs

\begin{tabular}{|c|c|c|c|c|c|c|}
\hline & Opinion & B1 & B2 & A1 & $\mathrm{A} 2$ & A3 \\
\hline $\mathrm{CoF}$ & \multirow{3}{*}{ Team 1} & 4.00 & 4.00 & 4.00 & 4.00 & 4.00 \\
\hline PoF & & 3.10 & 9.00 & 2.10 & 3.20 & 2.70 \\
\hline DoF & & 2.00 & 2.00 & 1.00 & 1.90 & 2.00 \\
\hline $\mathrm{CoF}$ & \multirow{3}{*}{ Team 2} & 3.66 & 3.66 & 3.33 & 3.33 & 3.33 \\
\hline PoF & & 2.50 & 9.00 & 1.90 & 2.80 & 3.30 \\
\hline DoF & & 2.33 & 2.00 & 1.66 & 1.76 & 2.66 \\
\hline $\mathrm{CoF}$ & \multirow{3}{*}{ Average } & 3.83 & 3.83 & 3.67 & 3.67 & 3.67 \\
\hline PoF & & 2.8 & 9.00 & 3.00 & 3.00 & 2.66 \\
\hline DoF & & 2.17 & 2.00 & 1.33 & 1.83 & 2.33 \\
\hline
\end{tabular}

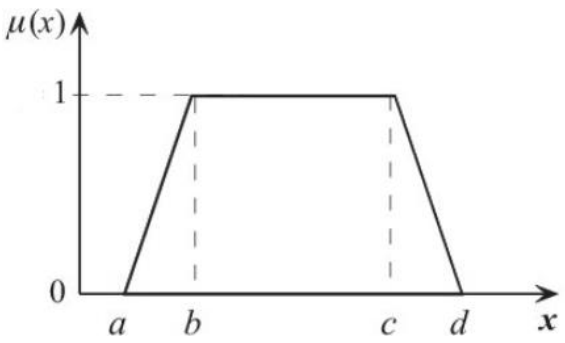

Figure 7

Trapezoidal fuzzy membership function 


$$
\mu_{A_{i}}(x)=\left\{\begin{array}{ccc}
0 & \text { if } & x \leq a_{i} \\
\frac{x-a_{i}}{b_{i}-a_{i}} & \text { if } & a_{i} \leq x \leq b_{i} \\
1 & \text { if } & b_{i} \leq x \leq c_{i} \\
\frac{d_{i}-x}{d_{i}-c_{i}} & \text { if } & c_{i} \leq x \leq d_{i} \\
0 & \text { if } & d_{i} \leq x
\end{array}\right.
$$

where $a_{i}, b_{i}, c_{i}, d_{i}$ are the membership function parameters, and $a_{i} \neq b_{i}, c_{i} \neq d_{i}$.

The proposed F-FMEA method uses both qualitative and quantitative perspectives of three inputs and one output parameter, classified as Probability of Failure $(P o F)$, Consequence of Failure $(C o F)$, and Detectability of Failure $(D o F)$ and Risk Priority Number $(R P N)$. The fuzzy membership function parameters are specified in Table 3, and illustrated in Figures 8-11.

Table 3

Membership Functions

\begin{tabular}{|c|c|c|c|}
\hline \multirow{3}{*}{$\mathrm{CoF}$} & $\mathrm{C} 1$ & Low & $\mu_{\text {Low }}=f:(0,0,1,3)$ \\
\hline & $\mathrm{C} 2$ & Medium & $\mu_{\mathrm{Med}}=f:(1,3,4,6)$ \\
\hline & $\mathrm{C} 3$ & High & $\mu_{\mathrm{H}}=f:(4,6,10,10)$ \\
\hline \multirow{3}{*}{$P o F$} & $\mathrm{O} 1$ & Improbable & $\mu_{\mathrm{Imp}}=f:(0,0,1,3)$ \\
\hline & $\mathrm{O} 2$ & Occasional & $\mu_{\mathrm{Occ}}=f:(1,3,4,6)$ \\
\hline & $\mathrm{O} 3$ & Probable & $\mu_{\text {Pro }}=f:(4,6,10,10)$ \\
\hline \multirow{3}{*}{$D o F$} & D1 & Detectable Easily & $\mu_{\mathrm{E}}=f:(0,0,1,3)$ \\
\hline & D2 & Detectable & $\mu_{\text {Det }}=f:(1,3,4,6)$ \\
\hline & D3 & Detectable with Difficulty & $\mu_{\mathrm{Dif}}=f:(4,6,10,10)$ \\
\hline \multirow{4}{*}{$P R N$} & R1 & Action is Unnecessary & $\mu_{\mathrm{Unn}}=f:(0,0,1,3)$ \\
\hline & R2 & Action is Suggested & $\mu_{\text {Sug }}=f:(1,3,4,6)$ \\
\hline & R3 & Action is Needful & $\mu_{\mathrm{N}}=f:(4,6,7,9)$ \\
\hline & $\mathrm{R} 4$ & Action is Very Needful & $\mu_{\mathrm{VN}}=f:(7,9,10,10)$ \\
\hline
\end{tabular}

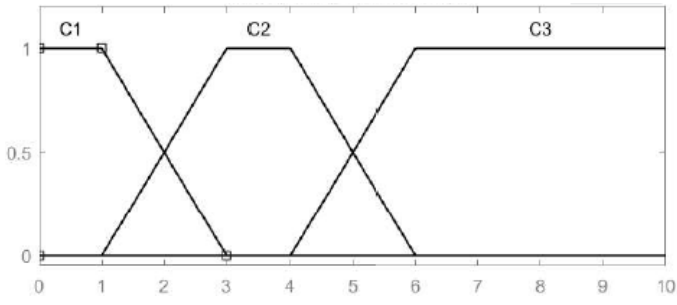

Figure 8

Input variable " $\mathrm{CoF}$ 


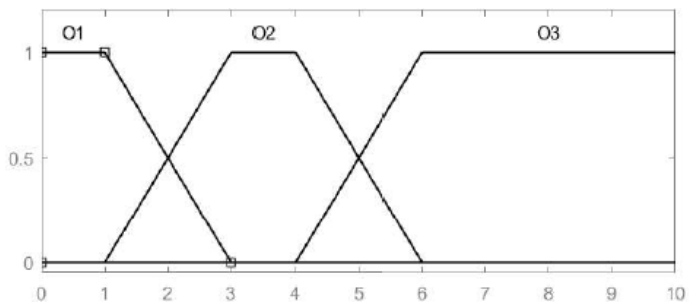

Figure 9

Input variable "PoF"

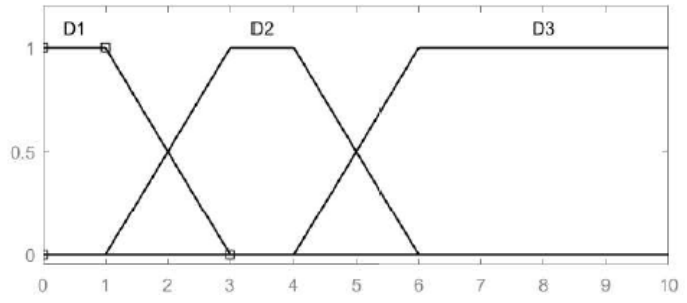

Figure 10

Input variable "DoF"

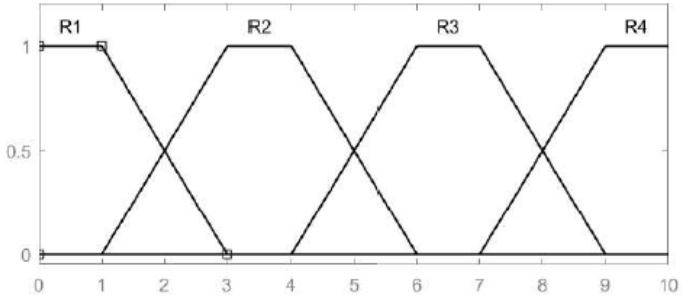

Figure 11

Output variable "Risk Priory Number"

In Table 4, the rule-base of the Fuzzy-based FMEA is defined in an IF-THEN structure, and the Zadeh-norms are used, i.e. minimum operator as AND connection, and the maximum operator as OR connection. Accordingly, following the composition sub-process, the $R P N$ is calculated using defuzzification methods for each event.

Table 4

The Rule Base of FMEAs

\begin{tabular}{|c|}
\hline$I F \mathrm{C} 1 A N D$ O1 AND D1 THEN R1 \\
\hline$I F \mathrm{C} 1 A N D \mathrm{O} 2 A N D \mathrm{D} 1$ THEN R2 \\
\hline$I F \mathrm{C} 1 A N D$ O1 $A N D$ D2 THEN R2 \\
\hline$I F \mathrm{C} 1 A N D$ O2 AND D2 THEN R3 \\
\hline$I F \mathrm{C} 2 A N D$ O1 AND D1 THEN R2 \\
\hline
\end{tabular}




\begin{tabular}{|c|}
\hline$I F \mathrm{C} 2$ AND O2 AND D1 THEN R3 \\
\hline$I F \mathrm{C} 2 A N D$ O1 AND D2 THEN R3 \\
\hline IF $\mathrm{C} 2$ AND O2 AND D2 THEN R3 \\
\hline IF $\mathrm{C} 3$ OR O3 OR D3 THEN R4 \\
\hline
\end{tabular}

Table 4 demonstrates the results of the original and modified systems. The results of the original system, where the evaluations are based on the average of expert opinions, are shown in the CoG and CoA columns referring to both F-RPN and Relative FRPN values. The columns SCoG and SCoAG show the result of the proposed F-FMEA improving by the summative defuzzification method when the opinions of the expert groups are evaluated separately, and then summarized.

Table 5

Result of comparison with the results of publication [1]

\begin{tabular}{|c|c|c|c|c|c|c|c|c|}
\hline \multirow{2}{*}{ Failure } & \multicolumn{4}{|c|}{ F-RPN } & \multicolumn{4}{c|}{ Relative FRPN [\%] } \\
\cline { 2 - 10 } & CoG & CoA & SCoG & SCoAG & CoG & CoA & SCoG & SCoAG \\
\hline B1 & 6.04 & 6.2 & 5.892 & 6.111 & 18.443 & 18.96 & 18.327 & 18.64 \\
\hline B2 & 8.94 & 9.00 & 8.94 & 9.00 & 27.298 & 27.52 & 27.807 & 27.46 \\
\hline A1 & 4.77 & 4.5 & 4.995 & 4.967 & 14.565 & 13.76 & 15.537 & 15.15 \\
\hline A2 & 6.5 & 6.5 & 6.21 & 6.386 & 19.847 & 19.88 & 19.316 & 19.48 \\
\hline A3 & 6.5 & 6.5 & 6.113 & 6.312 & 19.847 & 19.88 & 19.014 & 19.26 \\
\hline
\end{tabular}

Based on the case study result, the following conclusions can be drawn:

- $\quad$ failure B2 has the highest F-RPN and Relative FRpN numbers;

- $\quad$ failure A1 has the smallest F-RPN and Relative FRpN numbers;

- $\quad$ all the defuzzification methods generate close relative RPN [\%] value for $\mathrm{B} 1, \mathrm{~A} 2$, and $\mathrm{A} 3$.

- $\quad$ the F-FMEA with summative defuzzification gives more expressive results according to the experts. This can be seen from the results that for A2 and A3, the traditional methods give the same results for both RPN and Relative RPN, whereas the summation methods differentiate them better.

- $\quad$ it can be observed that for B2, both CoG and SCoAG give the same result, just like for CoA and SCoAG. This situation arises because this failure is evaluated equally by the two expert groups.

\section{Conclusion}

Nowadays, due to increased quality requirements, optimizing the manufacturing process has become crucial. However, measuring all possible settings and parameters, which affect the quality requirements is both cost- and timeconsuming, and in some cases is not possible at all. The widely used engineering technique Failure Modes and Effects Analysis (FMEA) is an excellent tool for 
preventing any possible defects, which may occur in the system, design, process, or service. However, the applicability of the method is limited by the fact that both quantitative and qualitative parameters can be observed among the risk factors, which should be handled adequately in order to obtain a realistic result. The Fuzzy-FMEA is an extension of the traditional FMEA method, which is able to handle the above-mentioned problem.

The F-FMEA can be used effectively when the analysis is conducted based on the opinion of a single expert. However, if multiple opinions of different experts are available a modified method is needed to ensure more reliable analysis. As an answer to this problem, the authors of this paper propose a novel F-FMEA method using Summative defuzzification (SCog and SCoAG). In this case, the opinions of the different experts are evaluated separately, and the overall result is composed based on the obtained results using a defuzzification again.

After presenting the theoretical basics, a case study was investigated in an F-FMEA system for assessing the risk of the bearing manufacturing process to demonstrate the usage of summative defuzzification, and the results were compared to the results of the traditional F-FMEA method. Based on the investigation it can be concluded that F-FMEA with summative defuzzification gives more expressive results according to the experts.

In future scientific research, the authors intend to:

- $\quad$ study the usage possibilities of fuzzy rule-based methods in the technical management decision making such as risk assessment;

- $\quad$ develop novel fuzzy rule-based methods using summative defuzzificaton in risk assessment-related fields.

\section{References}

[1] S. Koçak, E. Toth-Laufer and L. Pokorádi, "Fuzzy Failure Modes and Effects Analysis with Different Defuzzification Methods - A Case Study for Bearing Manufacturing Process," in IEEE $17^{\text {th }}$ International Symposium on Intelligent Systems and Informatics, Subotica, Serbia, 2019

[2] Gy. Czifra, P. Szabó, M. Míkva, J. Vaňová, "Lean Principles Application in the Automotive Industry," Acta Polytechnica Hungarica, Vol. 16, No. 5, pp. 43-62, 2019

[3] T. A. Carbone and D. D. Tippett, "Project risk management using the project risk FMEA," Engineering management journal, Vol. 16, No. 4, pp. 28-35, 2004

[4] R. D. Reid, "FMEA—something old, something new," Quality Progress, Vol. 38, No. 5, pp. 90-93, 2005

[5] G. Popov, B. K. Lyon and B. Hollcroft, \{Risk assessment: A practical guide to assessing operational risks, John Wiley \& Sons, 2016 
[6] E. Tóth-Laufer, M. Takács and I. J. Rudas, "Fuzzy logic-based risk assessment framework to evaluate physiological parameters," Acta Polytechnica Hungarica, Vol. 12, pp. 159-1782, 2015

[7] L. A. Zadeh, "Fuzzy sets," Information and control, Vol. 8, No. 3, pp. 338353,1965

[8] S. Koçak, "Fuzzy Logic and its Mechatronics Engineering," Repüléstudományi közlemények xxix. élfolyam, pp. 41-48, 2017

[9] E. H. Mamdani and S. Assilian, "Learning control algorithms in real dynamic systems," in th IFAC/IFIP International conference on digital computer applications to process control, Springer, 1974, pp. 13-74

[10] J. B. Bowles and C. E. Peláez, "Fuzzy logic prioritization of failures in a system failure mode, effects and criticality analysis," Reliability Engineering \& System Safety, Vol. 50, No. 2, pp. 203-213, 1995

[11] J. Balaraju, M. G. Raj and C. S. Murthy, "Fuzzy-FMEA risk evaluation approach for LHD machine-A case study," Journal of Sustainable Mining, Vol. 4, No. 18, pp. 257-268, 2019

[12] Kelvin P. L. Pun, Jason Rotanson, Cheung Chee-wah, Alan H.S., Chan, "Application of fuzzy integrated FMEA with product lifetime consideration for new product development in flexible electronics industry," Journal of Industrial Engineering and Management, Vol. 12, No. 1, pp. 176-200, 2019

[13] F. J. Ebert, "Fundamentals of design and technology of rolling element bearings," Chinese Journal of Aeronautics, Vol. 23, No. 1, pp. 123-136, 2010

[14] M. M. Khonsari and R. E. Booser, Applied tribology: bearing design and lubrication, John Wiley \& Sons, 2017

[15] Y. Yang, W. Yang and D. Jiang, "Simulation and experimental analysis of rolling element bearing fault in rotor-bearing-casing system," Engineering Failure Analysis, Vol. 92, pp. 205-221, 2018

[16] H. Cao, L. Niu, S. Xi and X. Chen, "Mechanical model development of rolling bearing-rotor systems: A review," Mechanical Systems and Signal Processing, Vol. 102, pp. 37-58, 2018

[17] O. Užga-Rebrovs and G. Kuḷešova, "Comparative analysis of fuzzy set defuzzification methods in the context of ecological risk assessment," Information Technology and Management Science, Vol. 20, No. 1, pp. 2529,2017

[18] S. Naaz, A. Alam and R. Biswas, "Effect of different defuzzification methods in a fuzzy based load balancing application," International Journal of Computer Science Issues (IJCSI), Vol. 5, No. 8, p. 261, 2011 
[19] L. Pokoradi, "Fuzzy logic-based risk assessment," AARMS, Academic and Applied Research in Military Science, Vol. 1, No. 1, pp. 63-73, 2002

[20] T. Obeidi, C. Larbes, A. Ilinca,G. F.T. Kebir, "Fuzzy Logic-based Maximum Power Point Tracking fora Solar Electric Vehicle," Acta Polytechnica Hungarica, Vol. 15, No. 7, pp. 133-156, 2018

[21] L. Pokorádi, B. Szamosi, "Fuzzy Failure Modes and Effects Analysis with Summative Center of Gravity DeFuzzification," $16^{\text {th }}$ IEEE International Symposium on Computational Intelligence and Informatics, CINTI 2015, Budapest, Magyarország : IEEE, (2015) pp. 147-150

[22] L. Pokorádi, "Systems and Processes Modelling," Debrecen: Campus Kiadó, 2008 (in Hungarian)

[23] Gnip, P., Vokorokos, L., \& Drotár, P. (2021) Selective oversampling approach for strongly imbalanced data. PeerJ Computer Science, 7, e604 